\title{
RANCANG BANGUN MODUL AUTOMATIC TRANSFER SWITCH (ATS) DENGAN MENGGUNAKAN PROGRAMABLE LOGIC CONTROLLER (PLC) OMRON SYSMAC CPM2A
}

\author{
Aprianus Siola ${ }^{1}$, Ruslim$^{2}$ \\ ${ }^{1,2}$ Teknik Elektro, Universitas Borneo Tarakan, Tarakan, Kalimantan Utara, Indonesia \\ 1aprianus.siola@gmail.com \\ 2ruslim1974@gmail.com
}

\begin{abstract}
The main power source which supplied from $P L N$ not always in "on" position forever or be able to supply to customers on an ongoing basis, is bound to happen someday or a repair outage at the plant. In anticipation of these cuts, then there are some consumers PLN that complements your home or company with the backup power generators. In the event of termination of the supply PLN, of course, the equipment needed to function as a voltage source switching from electricity to the generator. However, manually transfer requires a relatively longer time.

This research aims to design a PLC-based ATS or that serves to move the source voltage automatically. From the results of the design and implementation of the ATS found that the conditions of power failure or life energy operator is not required anymore. In addition the process in the removal of the source voltage is also shorter time.
\end{abstract}

Keywords-ATS, PLC, PLN, Electric Power.

Intisari-Sumber listrik utama yang disalurkan dari PLN tidak selamanya hidup atau dapat men-suplai ke konsumen secara terus menerus, suatu saat pasti akan terjadi pemadaman atau adanya perbaikan pada pembangkit. Untuk mengantisipasi dari pemadaman tersebut, maka ada beberapa konsumen PLN yang melengkapi rumah atau perusahaannya dengan pembangkit listrik cadangan yaitu genset. Jika terjadi pemutusan dari suplai PLN, tentunya dibutuhkan peralatan yang berfungsi sebagai pemindah sumber tegangan dari PLN ke genset. Namun demikian pemindah secara manual membutuhkan waktu yang relatif lebih lama.

Penelitian ini bertujuan untuk mendesain sebuah ATS berbasis PLC atau yang berfungsi untuk memindahkan sumber tegangan secara otomatis. Dari hasil desain dan implementasi ATS diperoleh bahwa dalam kondisi PLN mati atau hidup tidak diperlukan lagi tenaga operator. Selain itu waktu proses dalam pemindahan sumber tegangan juga lebih singkat.

Kata Kunci-ATS, PLC, PLN, Sumber Daya Listrik.

\section{PENDAHULUAN}

Umumnya sumber listrik utama yang disalurkan dari PLN tidak selalu menyalurkan sumber listrik secara terus menerus, oleh karena itu untuk menjaga kualitas, stabilitas dan keandalan maka harus ada proses pemeliharaan dan perawatan baik secara terjadwal pada kondisi normal maupun darurat pada kondisi terjadi gangguan, dan juga kemungkinan kekurangan daya pada konsumen tertentu pada waktu beban puncak dan kenaikan beban temporer pada sisi konsumen. Apabila kondisi gangguan seringkali terjadi, maka dapat mengakibatkan terganggunya stabilitas keamanan, perekonomian, terutama pada aktivitas pelayanan kepada masyarakat. Untuk mengatasi terputusnya layanan sumber listrik, maka beberapa konsumen memilih alternatif dengan menyediakan pembangkit listrik darurat seperti genset, dengan tujuan menyediakan kebutuhan sumber listrik secara kontinyu.

Pengoperasian sumber listrik PLN dan sumber listrik genset dapat dilakukan secara manual maupun secara otomatis. Pemasangan ATS dengan menggunakan PLC merupakan solusi yang efektif dalam pengalihan suplai sumber listrik dari PLN ke Pembangkit listrik cadangan Genset. Sistem ini dapat bekerja sewaktu suplai arus dari PLN terputus, maka sumber listrik cadangan Genset dapat menyalurkan arus listrik dengan efektif sehingga memperlancar segala aktifitas.

Sistem ATS untuk backup dengan menggunakan PLC berfungsi untuk menjaga kontinuitas penyaluran daya ke beban. Selain itu, untuk membantu tempat-tempat yang sering mengalami pemadaman PLN dan memerlukan suplai dari sumber cadangan dalam waktu cepat. ATS dalam penyuplaian beban diatur agar genset tidak terjadi pembebanan penuh. Perancangan ATS berdasarkan standart yang berlaku guna memenuhi keamanan peralatan listrik. ATS ini dirancangan berdasarkan teoriteori yang relevan dan diakui. Perancangan ATS untuk backup daya menggunakan PLC terdiri dari dua bagian yaitu, hardware dan software. Perancangan hardware terdiri dari relai sebagai sensor tegangan baik yang bersumber dari maupun genset, sistem kendali ATS berupa PLC dan kontaktor sebagai penghubung daya. Sedangkan software berfungsi sebagai aplikasi untuk desain ladder [4].

\section{LANDASAN TEORI}

\section{A. Programmable Logic Controller (PLC)}

Programmable Logic Controller (PLC) pada dasarnya adalah sebuah computer yang khusus dirancang untuk mengontrol suatu proses atau mesin. Proses yang 
dikontrol ini dapat berupa regulasi variable secara kontinu seperti pada sistem-sistem servo, atau hanya melibatkan control dua keadaan (on/of) sajatetapi dilakukan secara berulang-ulang seperti umum dijumpai pada mesin pengeboran, sistem konveyor, dan lain sebagainya.

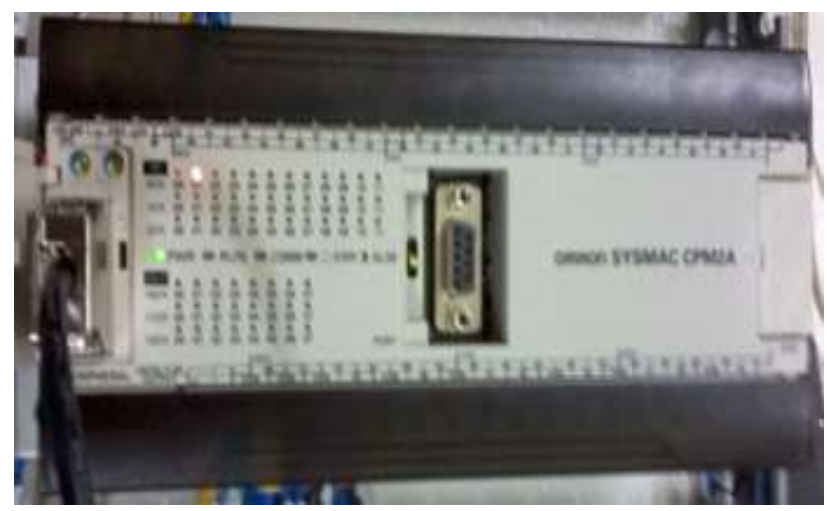

Gambar 1. Programmable Logic Controller

Fungsi dan kegunaan PLC sangat luas. Dalam prakteknya $P L C$ dapat dibagi secara umum dan secara khusus, Secara umum fungsi $P L C$ adalah sebagai berikut:

1. Sekuensial Control : PLC memproses input sinyal biner menjadi output yang digunakan untuk keperluan pemrosesan teknik secara berurutan (sekuensial), disini PLC menjaga agar semua step atau langkah dalam proses sekuensial berlangsung dalam urutan yang tepat.

2. Monitoring Plant : PLC secara terus menerus memonitor status suatu sistem (misalnya temperatur, tekanan, tingkat ketinggian) dan mengambil tindakan yang diperlukan sehubungan dengan proses yang dikontrol (misalnya nilai sudah melebihi batas) atau menampilkan pesan tersebut pada operator [1],[2].

B. Relai

Relai adalah komponen elektronika berupa saklar elektronik yang digerakkan oleh aruslistrik. Secara prinsip, relai merupakan tuas saklar dengan lilitan kawat pada batang besi (solenoid) di dekatnya Ketika solenoid dialiri arus listrik, tuas akan tertarik karena adanya gaya magnet yang terjadi pada solenoid sehingga kontak saklar akan menutup. Pada saat arus dihentikan, gaya magnet akan hilang, tuas akan kembali ke posisi semula dan kontak saklar kembali terbuka.Relay biasanya digunakan untuk menggerakkan arus/tegangan yang besar (misalnya peralatan listrik 4 ampere AC $220 \mathrm{~V}$ ) dengan memakai arus/tegangan yang kecil (misalnya 0.1 ampere 12 Volt DC).

\section{Kontaktor}

Kontaktor adalah suatu peralatan pemutus rangkaian listrik pada suatu sistem tenaga listrik, yang mampu untuk membuka dan menutup rangkaian listrik pada semua kondisi, termasuk arus hubung singkat, sesuai dengan ratingnya. Juga pada kondisi tegangan yang normal ataupun tidak normal.
Syarat-syarat yang harus dipenuhi oleh suatu PMT agar dapat melakukan hal-hal diatas, adalah sebagai berikut :

1. Mampu menyalurkan arus maksimum sistem secara terus-menerus.

2. Mampu memutuskan dan menutup jaringan dalam keadaan berbeban maupun terhubung dengan singkat tanpa menimbulkan kerusakan pada pemutus tenaga itu sendiri.

3. Dapat memutuskan arus hubung singkat dengan kecepatan tinggi agar arus hubung singkat tidak sampai merusak peralatan sistem, membuat sistem kehilangan kestabilan, dan merusak pemutus tenaga itu sendiri [3].

\section{Uninterruptible Power Supply (UPS)}

UPS adalah (uninterruptible power supply) yang artinya Penyedia Tegangan Tak terjeda secara umum bila diartikan secara harfiah pengertian UPS adalah penyedia suplai listrik yang tidak terputus.

Pengertian yang umum dimengerti oleh kebanyakan orang UPS itu alat untuk memberikan tenaga listrik cadangan pada komputer jika listrik utama (PLN) mati.Padahal pengertian UPS itu lebih luas lagi. Selain dari fungsi tadi, alat ini juga berguna untuk memberikan proteksi kepada beban misal komputer tentu beserta datanya dari kerusakan yang diakibatkan oleh sumber listrik yang kurang bagus.

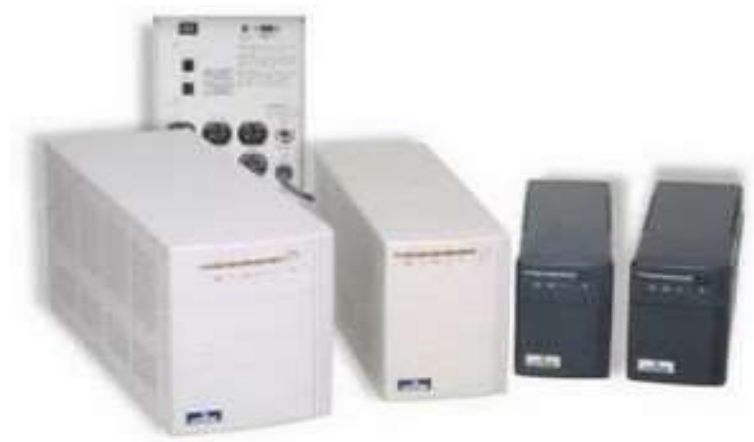

Gambar 2. Uninterruptible Power Supply

\section{E. Genset}

Genset atau kepanjangan dari generator set adalah sebuah perangkat yang berfungsi menghasilkan daya listrik. Disebut sebagai generator set dengan pengertian adalah satu set peralatan gabungan dari dua perangkat berbeda yaitu engine dan generator atau alternator. Engine sebagai perangkat pemutar sedangkan generator atau alternator sebagai perangkat pembangkit listrik. Engine dapat berupa perangkat mesin diesel berbahan bakar solar atau mesin berbahan bakar bensin, sedangkan generator atau alternator merupakan kumparan atau gulungan tembaga yang terdiri dari stator ( kumparan statis ) dan rotor (kumparan berputar).

\section{METODE PENELITIAN}

Tempat pelaksanaan penelitian dilakukan di Laboratorium Teknik Elektro Universitas Borneo Tarakan, untuk melaksanakan penelitian mengenai pembuatan alat ATS ini dilaksanakan selama 2 (dua) bulan 
setelah diterimanya proposal penelitian ini, untuk dapat menyelesaikan tugas akhir ini maka penulis menerapkan beberapa metode diantaranya Studi literatur dan perancangan dan pembuatan ATS. Peneliti melakukan penelitian dengan tahapan pengambilan data tentang $A T S$, pembuatan atau desain alat $A T S$, simulasi sistem kontrol pada peralatan $A T S$, penyesuaian program dengan i, dan implementasi $A T S$.

Untuk melaksanakan penelitian ini, beberapa parameter dan peralatan yang dibutuhkan untuk menunjang penelitian ini. peralatan - peralatan yang digunakan dalam proses dari sistem ATS adalah sumber PLN, genset, multimeter, laptop, dan software $C X$ Programmer. Bahan-bahan yang digunakan dalam perancangan sistem ATS meliputi Programmable Logic Controller (PLC), relai, kontaktor, MCB,UPS, tombol emergensi, selektor, trafo $C T$,dan lampu $R S T$.

\section{HASIL DAN PEMBAHASAN}

\section{A. Logaritma Ladder ATS berbasis PLC Omron SYSMAC CPM2A}

Dari hasil desain digram ladder yang telah dilakukan pengujian maka dapat dijelaskan sistem kendali ATS berbasis $P L C$ sebagai berikut :

\section{Kontaktor PLN ON}

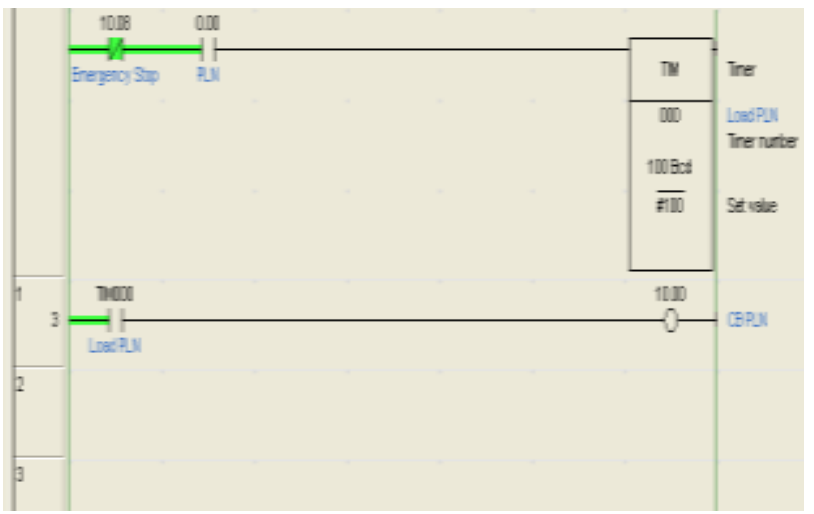

Gambar 3. Diagram ladder kontaktor PLN terbuka

Gambar 3 memperlihatkan sistem kendali $P L C$ ketika line PLN dalam kondisi Off atau padam, dimana kontak terbuka dari port 0.00 berada pada kondisi terbuka.

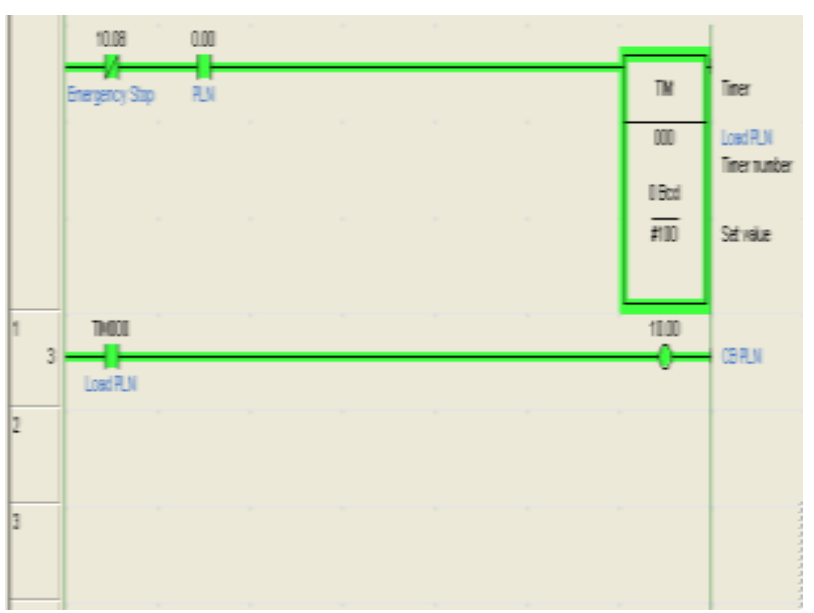

\section{Gambar 4. Diagram ladder kontaktor PLN tertutup}

Jika saluran PLN dalam kondisi hidup maka yang terjadi adalah sebagaimana pada Gambar 4, dimana kontak dari port 0.00 akan tertutup. Pada saat PLN mulai hidup biasanya tegangan PLN tidak langsung stabil, hal ini akan beresiko pada peralatan yang terpasang sebagai beban pada sistem tersebut. Oleh karena itu dibutuhkan waktu tunda untuk menghubungkan sumber tegangan dari PLN dengan beban. Dari sistem ATS yang dirancang pada penelitian ini fungsi tersebut dilakukan oleh timer 0.00. Timer 000 adalah timer on delay, dimana biner ini akan berada pada kondisi on setelah 10 detik sesuai dengan intruksi yang telah dimasukan, hitungan 10 detik disini adalah prediksi waktu yang dibutuhkan jalur PLN untuk berada pada kondisi tegangan yang stabil.

\section{Power Genset $O N$ dan $O F F$}

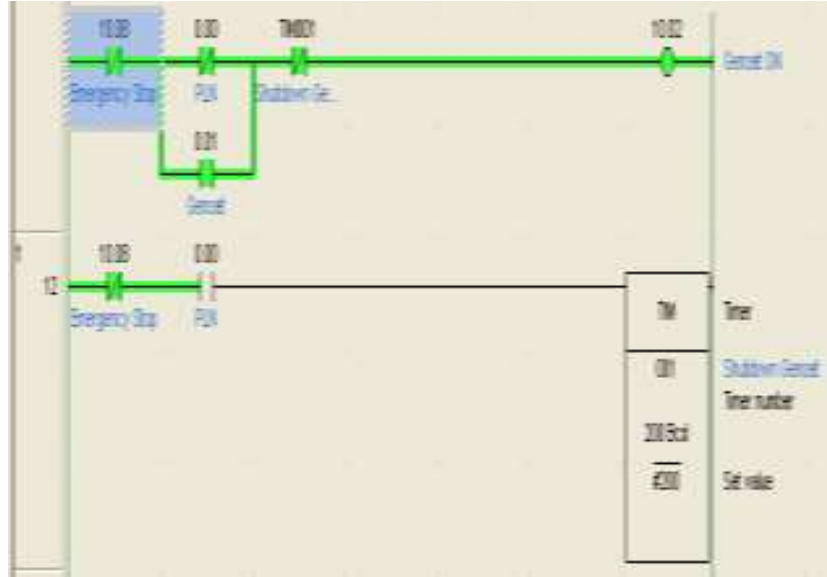

Gambar 5. Diagram ladder genset $O N$

Gambar 5 memperlihatkan ledder dimana power genset dalam keadaan terhubung yaitu, Jika pada koil 10.02 terbuka. Kemudian kondisi tersebut terjadi jika, posisi $N C$ dari port 0.00 dan posisi $N O$ dari port 0.01 bekerja. Power genset akan off jika timer 0.01 berada dalam kondisi on, dimana port $N C$ dari TIM001 terputus, hal ini terjadi jika sumber tegangan dari PLN kembali terhubung. Proses pemutusan power genset terjadi setelah 20 detik sejak jalur PLN terhubung.

\section{Start Genset}

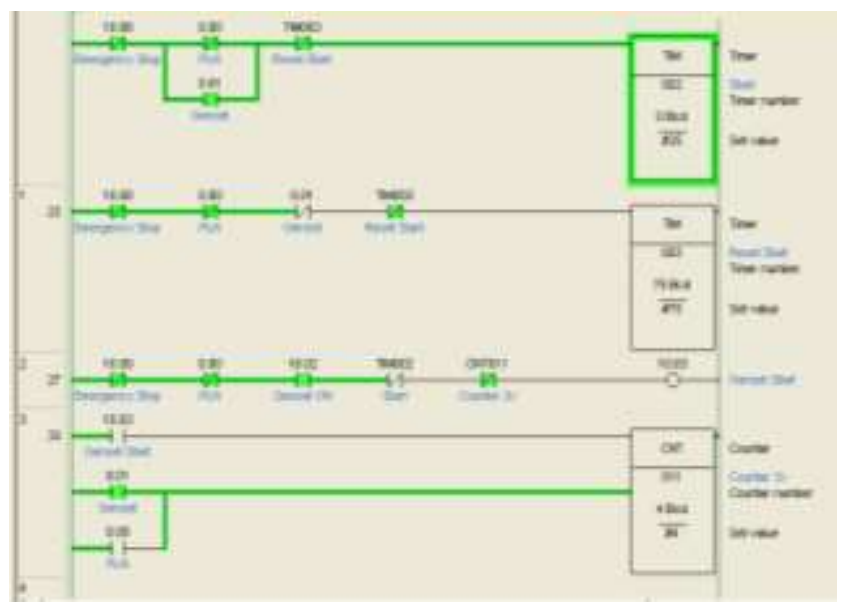




\section{Gambar 6. Diagram ladder start genset}

Gambar 6 memperlihatkan genset akan melakukan start ketika tegangan dari PLN padam, penjelasan dari ledder diatas yaitu ketika genset dalam keadaan hidup yaitu kontak dari 10.08, 0.00 akan tertutup dan timer 10.03 akan bekerja sebagai start genset jika dalam starter pertama hidup maka timer 003 akan mereset pada timer 002 untuk berhenti men-starter genset. Apabila dalam start genset pertama tidak hidup maka kontak CNT011 akan mengulang melakukan start genset kedua dan ketiga yaitu start genset sebanyak 3 kali.

\section{Kontaktor Genset ON}

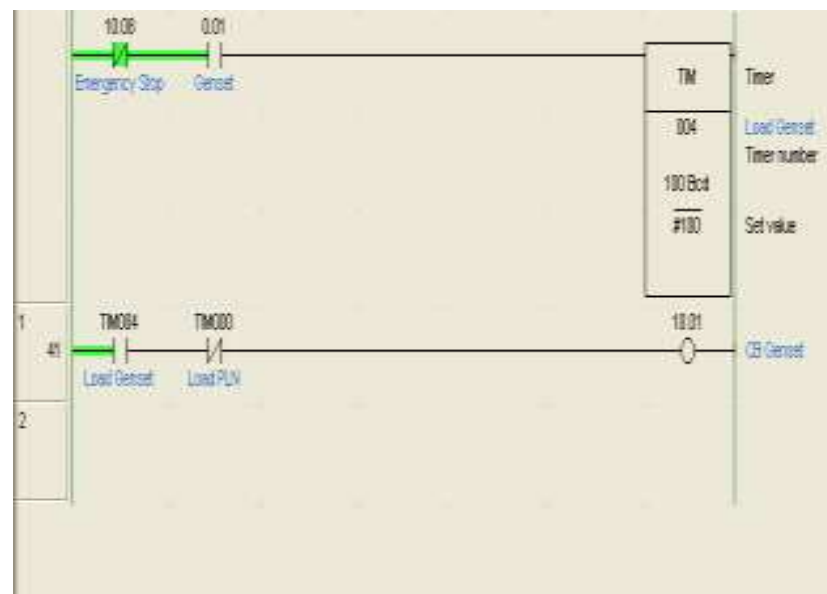

Gambar 7. Diagram ladder kontaktor genset terbuka

Gambar 7 memperlihatkan sistem kendali PLC ketika line genset dalam kondisi Off atau genset mati, dimana kontak $N O$ dari port 0.01 berada pada kondisi terbuka .

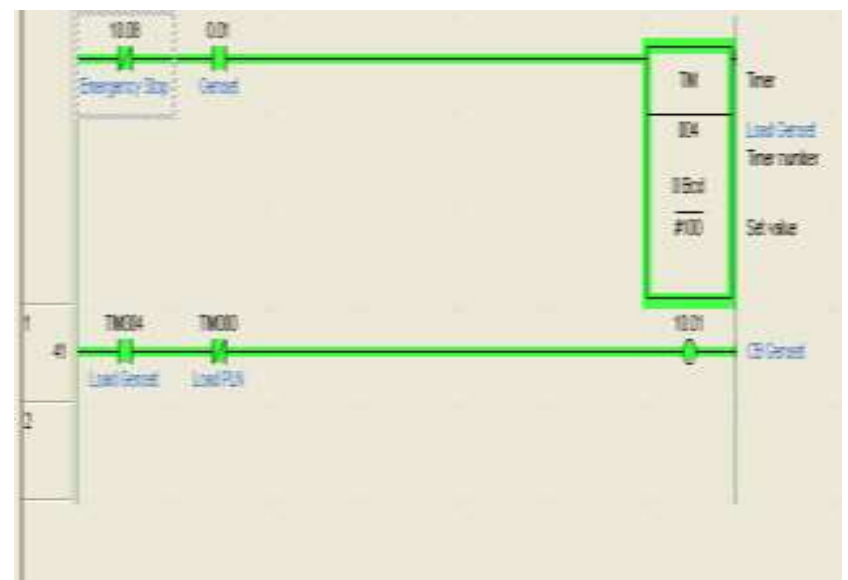

Gambar 8. Diagram ladder kontaktor genset tertutup

Gambar 8 memperlihatkan dimana kontak pada port 0.01 akan tertutup jika genset dalam posisi $O N$ atau hidup. Yaitu Dimana kontak dari TIM004 akan tertutup jika timer 004 bekerja, yaitu menunggu kestabilan tegangan dari genset selama 10 detik. Jika TIM004 pada posisi tertutup, kontak dari port 10.01 atau Kontaktor dari genset akan tertutup dan tegangan akan langsung masuk ke load atau beban.

\section{Emergency stop}

Pada emergency stop menggunakan satu tombol untuk on dan off, dimana fungsi ini bisa menggunakan Internal relai, Set reset, dan Counter. Pada penelitian saya untuk skripsi mencoba menggunakan Counter.

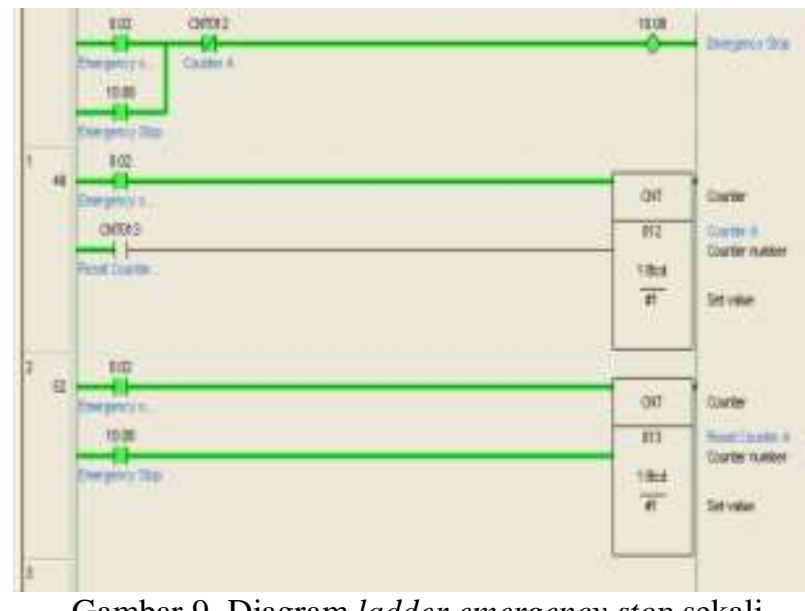

Gambar 9. Diagram ladder emergency stop sekali tekan

Gambar 9 diatas dapat dijelaskan pada saat tombol emergency ditekan $1 \mathrm{x}$ maka yang terjadi adalah kontak pada port 10.08 terbuka atau normaly open dan counter 012 akan memutus pada CNT012 yaitu normaly open. ketika itu sistem dari ATS akan berhenti.

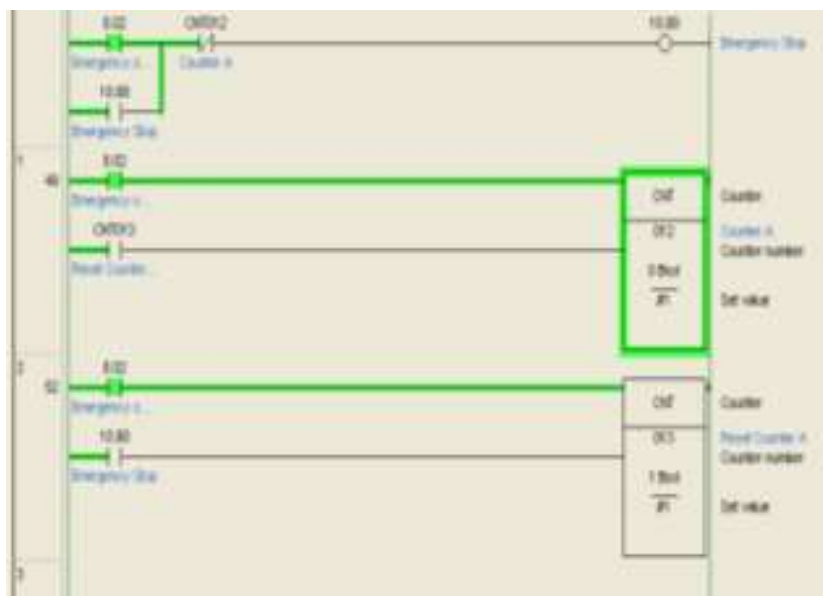

Gambar 10. Diagram ladder emergency stop dua kali tekan

Dari gambar 10 dapat dilihat yaitu ledder emergency stop, jadi jika tombol emergency di tekan 2x maka counter akan mereset CNT012, kemudian counter 012 akan di reset sama counter 013 yaitu memutus CNT013 sedangkan counter 013 akan direset sama kontak 10.08. jadi sistem dapat berjalan atau bekerja lagi.

\section{B. Pengujian sistem ATS menggunakan Genset Noqiwa} tipe EC700 CXF.

Implementasi hasil dari penelitian yang di dapat pada saat percobaan alat hingga alat bekerja sesuai dengan sistem yang dibuat dengan menggunakan software $C X$ programer yaitu sebagai berikut :

1. Pada saat sumber listrik PLN mati

Pada saat sumber listrik PLN mati kerja dari ATS akan menggantikan sumber tegangan dari Genset, yaitu 
dengan menghidupkan genset dan men-starter genset sampai hidup, ketika Genset hidup dan tegangan dari genset stabil yaitu $220 \mathrm{~V}$, maka Kontaktor 2 akan menutup dan tegangan akan langsung masuk ke load atau beban waktu yang dibutuhkan untuk memindahkan beban melalui Kontaktor 2 adalah 10 detik.

2. Pada saat sumber listrik PLN hidup

Pada saat sumber listrik PLN hidup kerja dari ATS akan mematikan genset dan sambil menunggu teganngan dari PLN stabil, ketika PLN sudah stabil yitu $220 \mathrm{~V}$, maka Kontaktor 1 akan tertutup sedangkan Kontaktor 2 akan terbuka, jadi tegangan akan masuk melalui Kontaktor 1 dan selingan waktunya adalah 10 detik.

3. Apa yang dilakukan ketika Gagal start pada Genset

Ketika pada saat men-starter genset gagal, maka yang perlu dilakukan adalah pengecekan sistem dari genset tersebut.

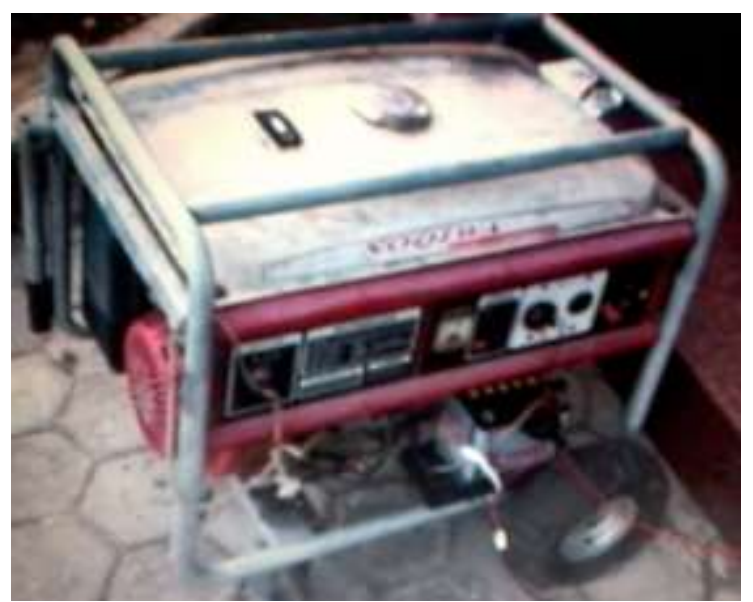

Gambar 11. Genset Noqiwa tipe EC700 CXF

\section{KESIMPULAN}

Dalam pembuatan rancang bangun modul Automatic Transfer Switch (ATS) dengan menggunakan Programmable Logic Controller (PLC) omron tipe SYSMAC CPM2A, dapat disimpulkan yaitu :

1. Apabila sumber utama PLN padam, pada saat yang bersamaan sistem ATS akan bekerja untuk menghidupkan sistem genset. Sistem ATS akan membuat kontaktor 1 yang terhubung pada PLN berada pada kondisi terbuka. Bersamaan dengan terbukanya kontaktor 1 , maka kontaktor 2 akan berada pada kondisi tertutup. Hasil pengujian menunjukan bahwa sistem ATS untuk pemindah sumber tegangan dari PLN ke genset mampu bekerja sesuai yang diharapkan.

2. Apabila sumber dari PLN tiba-tiba hidup maka sistem ATS diharapkan dapat bekerja untuk mengendalikan proses pemindahan sumber tegangan dari genset ke PLN. Proses ini terjadi dengan cara mematikan kontaktor 2 dan menghidupkan kontaktor 1. Hasil pengujian menunjukan bahwa proses pemindahan sumber ke sumber tegangan PLN bekerja sesuai dengan yang di harapkan.

3. Jika sumber tegangan dari PLN terputus selama kurang dari 5 detik diharapkan sistem pada genset tidak akan bekerja. Hasil pengujian menunjukan bahwa jika terjadi pemadaman PLN yang kurang dari 5 detik, genset tidak mengalami start.

4. Apabila terjadi gangguan pada sistem ATS yang disebapkan sumber dari genset atau sumber dari PLN yang dapat merusak peralatan ATS, untuk mengamankannya yaitu penyediaan tombol emergency berfungsi untuk mematikan semua sistem yang bekerja.

\section{UCAPAN TERIMA KASIH}

Terima kasih penulis ucapkan kepada segenap pihak yang secara langsung maupun tidak langsung telah berkontribusi baik terhadap proses penyusunan tulisan ini maupun dalam proses publikasinya. Terima kasih kepada para autor yang naskahnya penulis jadikan sebagai referensi.

\section{REFERENSI}

[1] Iwan Setiawan, 2006, Programmable Logic Controller (PLC) dan Teknik Perancangan Sistem Kontrol, Dell Publissing, Penerbit Andi, Yogyakarta.

[2] Handy wicaksono, 2009, Programmable Logic Controller. Teori, Pemograman dan aplikasinya dalam otomasi sistem, Yogyakarta.

[3] Febrio Nugrah Alganiy, 2001, KONTAKTOR SEBAGAI KOMPONEN PENGENDALI MOTOR LISTRIK, Palembang.I Ketut Wijaya, 2009, Penggunaan dan Pemilihan Pengaman Mini Circuit Breaker (MCB) Secara Tepat Menyebapkan Bangunan Lebih Aman Dari Kebakaran Akibat Listrik, Universitas Undiyana, Bali.

[4] HimawanWibowo, 2005, ANALISA TEKNOEKONOMI PEMAKAIAN GENSET DAN SUMBER PLN PADA TRANSMITER TVRI, Semarang 